\title{
Avaliação da Aprendizagem: um Desafio para o Docente
}

\author{
Edjonas Silvana Lopes ${ }^{1}$; Anna Christina Farias de Carvalho ${ }^{2}$
}

Resumo: Esse artigo tem como objetivo, conceituar e compreender a finalidade da avaliação na aprendizagem, sua função educacional e porque muitos docentes tem "pecado" no assunto. No primeiro momento, abordamos a necessidade iminente do homem em avaliar tudo ao seu redor, lembrando que constantemente somos avaliados e estamos avaliando nossos semelhantes e ações. Sem esquecer que é próprio da natureza humana procurar culpados para os erros e na educação não é diferente. Há mais gente procurando e apontando culpados para os problemas da educação do que pessoas procurando soluções viáveis para solucioná-los. No segundo momento usamos como base a obra de Hamilton Werneck "Prova, provão, camisa de força da educação (1995)", onde o autor faz comparações de animais as ações e práticas dos professores, ou seja, a postura do educador diz que tipo de animal ele é ou assemelha-se. Por fim, concluímos esclarecendo que avaliação da aprendizagem não tem nada a ver com castigo ou punições para o aluno, mas é uma ferramenta diagnóstica para aferir o conhecimento ou dificuldades do mesmo, só assim o professor poderá progredir no ensino, fazer as mudanças ou correções possíveis, sempre priorizando o ensino de qualidade.

Palavras-chaves: Avaliação. Aprendizagem. Ensino.

\section{Evaluation of Learning: A Challenge for Teachers}

\begin{abstract}
This article aims, conceptualize and understand the purpose of evaluation in learning, their real educational function and because many teachers have "sin" in the subject. At first, we address the imminent need of man to evaluate everything around you, remembering that we are constantly evaluated and we are evaluating our fellowmen. Without forgetting that it is human nature to seek blame for mistakes and education is no different. There are more people looking and pointing blame for the problems of education than people looking for viable solutions to solve them. In the second phase we use as a basis the work of Hamilton Werneck "Support, Provão, straitjacket of education" where the author makes animals comparisons actions and practices of teachers, ie, the position of the teacher says what kind of animal it it is or resembles. Finally, we conclude by clarifying that evaluation of learning has nothing to do with punishment or punishments for the student, but it is a diagnostic tool to assess the knowledge or difficulties in, just so the teacher can progress in education, make changes or corrections possible, always giving priority to quality education.
\end{abstract}

Keywords: Evaluation. Learning. Teaching.

\footnotetext{
${ }^{1}$ Mestrando em Ciências da Educação pela Unisullivan University. Graduado e Especialista em Biologia Geral pela Faculdade de Formação de Professores de Araripina-PE- FAFOPA.

${ }^{2}$ Doutora em Sociologia pela Universidade Federal da Paraíba - UFPB. Pós - Doutora em Letras pela UFPB. Professora aposentada da Universidade Regional do Cariri - URCA. Pesquisadora do Núcleo de Estudos em Ciência, Espiritualidade e Filosofia - NECEF/ URCA. Email: anna_crica@hotmail.com.
} 
Id on Line Revista Multidisciplinar e de Psicologia

Id on Line Multidisciplinary and Psycology Journal

\section{Introdução}

Avaliação da Aprendizagem: um desafio para o docente é o tema desse artigo. Sabese que avaliação é uma constante em nosso dia a dia, seja em casa, no trabalho, na rua ou no lazer estamos sempre avaliando, emitindo um juízo de valor a algo ou a alguém. Avaliação faz parte da vida humana em todos os aspectos e faixa etária, tendo em vista que seu significado é "dar valor a", constantemente avaliamos e somos avaliados.

De acordo com Luckesi (2008), a avaliação é um julgamento sobre uma realidade concreta ou sobre uma prática, à luz de critérios claros, estabelecidos prévia ou concomitantemente, para tomada de decisão. Desse modo, três elementos se fazem presentes no ato de avaliar: a realidade ou prática julgada, os padrões de referência, que dão origem aos critérios de julgamento, e o juízo de valor.

Avaliar vem do latim. Segundo Luckesi (2006, p.92 Apud COSTA, 2013) deriva da junção de a-valere, que quer dizer "dar valor a" [...]. Conforme o dicionário de Ferreira Júnior (2011, p. 121) avaliar é "determinar a valia ou o valor de". Enfim, avaliar é realmente emitir um juiz de valor a algo ou alguém, o que fazemos constantemente. Porém, esse juízo de valor é dado mediante convicções pessoais e compreensões do que se ver, e esse julgar não raro pode nos enganar, nos dar uma compreensão superficial do real, tendo em vista que a verdade de um indivíduo não necessariamente seja a verdade absoluta.

No tocante a avaliação da aprendizagem, esse tema é polêmico e delicado, sendo que o avaliador, em nosso caso é o professor e este por muitas vezes tem usado o exame avaliativo como forma de punição ao aluno, fazendo algo totalmente diferente daquilo que foi ensinado em sala de aula. Se não foi ensinado o conteúdo em sala como pode o aluno saber a resposta na avaliação? Se a avaliação revela aquilo que o professor fez da turma, como pode esse profissional tentar prejudicar seus alunos?

Segundo Tyler, (1981, p.166 Apud SAKAMOTO, 2010, p.1) sobre a temática, ele diz:

O termo avaliação da aprendizagem é recente, apareceu em 1930, e é atribuído a Ralph Tyler, educador norte americano que se dedicou à questão de um ensino que fosse eficiente. Os pesquisadores norte-americanos da área de avaliação de aprendizagem definem o período de 1930 a 1945, como o período "tyleriano" da avaliação da aprendizagem. O termo foi introduzido, mas a prática continuou sendo baseada em 
provas e exames, apesar de vários educadores acreditarem que a avaliação poderia e deveria subsidiar um modo eficiente de fazer ensino.

Se avaliação da aprendizagem surgiu no intuito de melhorar o ensino, porque será que tomou um rumo diferente? Os instrumentos para avaliação são infinitos, desde a velha avaliação escrita a seminário, trabalhos em equipe, pesquisa, observação participativa, observação prática e avaliação oral, entre outras. Na verdade a avaliação escolar é um subsidio para o professor como elemento de reflexão contínua sobre sua prática, como mediação de uma nova postura frente às dificuldades enfrentadas pelos alunos.

Infelizmente a avaliação é pautada numa prática temida e assustadora, o que impede o despertar pelo gosto de estudar. Nesse caso, cabe-nos buscar soluções possíveis para mudar e aperfeiçoar essa prática.

\section{Avaliação da Aprendizagem}

$\mathrm{O}$ ato de avaliar faz parte do dia a dia das pessoas, cada ser humano em momentos e contextos diferentes. Costumeiramente avaliamos as ações, atitudes e expressões dos nossos semelhantes, emitindo consequentemente um juízo de valor a cada situação, juízo esse que pode ser positivo ou negativo, dentro daquilo que temos como verdade e correto, bom ou mal. Mas, o que está implícito aqui ao avaliar o próximo, chama-se aprendizagem, conhecimento adquirido através da educação familiar e escolar.

Segundo Luckesi (2000, p.1) "a avaliação da aprendizagem escolar se faz presente na vida de todos nós, de alguma forma, estamos comprometidos com atos e práticas educativas." Realmente, é quase inevitável viver sem avaliar, sem atribuir um valor a algo ou ações, principalmente, aos profissionais da educação. Mas o problema não está em avaliar somente, mas na maneira, na ideia e na intenção do avaliador, isso sim, é preocupante.

É comum ouvir uma pessoa avaliando a educação dado ao filho de alguém, principalmente quando esse filho não é um bom exemplo a ser seguido. Porque apontar as "falhas" dos outros é muito fácil, digamos que até prazeroso quando vemos por uma ótica 
Id on Line Revista Multidisciplinar e de Psicologia

Id on Line Multidisciplinary and Psycology Journal

capitalista e competitiva do mundo atual, do mundo moderno, mas conhecer e compreender o processo pelo qual este passou, não é fácil, muito menos tarefa para qualquer pessoa.

Na educação escolar a avaliação tem sido colocada como um "bicho papão", uma prova da incompetência do estudante. Infelizmente essa postura tem travado ou bloqueado muitos alunos. Sem levar em consideração que a avaliação escolar ao mesmo tempo em que avalia o estudante, avalia primeiramente o docente, a escola, a coordenação pedagógica, a gestão escolar e a interação com a família.

A avaliação não pode ser colocada como uma ferramenta de exclusão, onde aquele que não alcançou a meta desejada pelo docente é inferior ou desmerece uma nova oportunidade educacional (DIAS e OLIVEIRA, 2017). Éexatamente este contexto que a escola precisa dar mais atenção, o que não sabe ou não acompanha o desempenho da turma. A avaliação é uma "faca" de dois gumes, um lado "corta" a favor do professor e o outro a favor do estudante. Se o aluno não aprende ou não vai bem nas avaliações, cabe aqui analisar uma série de fatores que influenciou nesse resultado, tais como, a didática do docente, os recursos utilizados no ensino, o empenho do discente, o apoio familiar, enfim, toda as ferramentas e recursos utilizados desde o ensino até a avaliação propriamente dita.

Luckesi (2008, p.33) caracteriza a avaliação com as seguintes palavras: “A avaliação pode ser caracterizada como uma forma de ajuizamento de qualidade do objeto avaliado, fator que implica em tomada de posição a respeito do mesmo, para aceita-lo ou para transformá-lo.”

Nesse sentido, Luckesi deixa claro seu pensar sobre a avaliação, para ele o ponto de partida para qualquer prática de avaliação é a disposição para acolher, isto é, aceitar as coisas como são, como estão no momento avaliado, boas ou ruins, bonitas ou feias, e partindo daí sim poder emitir um conceito, um julgamento preciso da situação e conseguintemente planejar intervenções necessárias para corrigir algo ou desenvolver o que ainda não existe.

Para Luckesi (2000, p.1) para corroborar com a temática ele ainda diz:

Chega de confundir avaliação da aprendizagem com exames. A avaliação da aprendizagem, por ser avaliação, é amorosa, inclusiva, dinâmica e construtiva, diversas dos exames, que não são amorosos, são excludentes, não são construtivos, são classificatórios. A avaliação inclui, traz para dentro; os exames selecionam, excluem, marginalizam. 
Id on Line Revista Multidisciplinar e de Psicologia

Id on Line Multidisciplinary and Psycology Journal

Mediante as sábias palavras do autor citado, pode-se dizer que todo aquele que tem um mínimo de conhecimento sobre educação de qualidade, concorda que avaliar não é apenas diagnosticar os erros do discente, classificando como incapaz ou como reta final da avaliação. Se agir dessa maneira, o professor está atestando sua incompetência pedagógica e engessando o seu de desenvolvendo enquanto profissional e principalmente o do estudante rumo a uma aprendizagem significativa.

Quando a avaliação é inclusiva, ela não assusta o avaliado. Ela deixa na mente deste a certeza que o professor está cumprindo com questões burocráticas da instituição de ensino, mas sempre foi e permanece como apoio e amigo dele, que usará os pontos negativos para lhe ajudar a crescer, enquanto aluno e cidadão. Na avaliação defendida pelo autor e por tantos outros, o seu objetivo não é excluir, não classificá-los no intuito de marginalizá-los, mas deve ser apenas uma etapa ou ferramenta de aproximação, da constatação que os objetivos de ensino foram atingidos, ou seja, que o professor realmente conseguiu a proeza de unir teoria e prática, o discurso com a realidade, enfim, fez seu papel com dignidade.

Avaliar a luz do dicionário Ferreira Junior, (2011, p. 121) significa “determinar a valia ou o valor de", isso quer dizer que o professor ao avaliar um estudante ele emite um valor a sua aprendizagem, estabelece um escala de 0 a 10, ou não, para "medir" ou avaliar seu desenvolvimento intelectual. Se a nota da avaliação não for acima da média esperada, préestabelecida pelo docente e pela escola, obviamente este estudante está em maus lençóis, correndo o risco de necessitar de uma recuperação ou até mesmo de ficar reprovado. Até aí, tudo bem, mas queremos chamar atenção para o que está implícito nesse processo, como saber se o docente ensinou tal qual ele cobrou na avaliação? Como precisar que a metodologia, a técnica, as palavras usadas estavam conforme a rotina em sala de aula? E finalmente, sabemos que o ser humano é um ser complexo e cheio de emoções, influenciado por "forças" externas, como problemas familiares, problemas de saúde, má alimentação, problemas financeiros, enfim, uma série de fatores que podem deixar o estudante despreparado para ser avaliado naquele determinado momento.

O ideal seria conhecer bem a clientela escolar, seus anseios, aptidões, realidade socioeconômica, seus familiares, pois assim, o professor poderia traçar um plano ou projeto de avaliação diferenciada, com técnicas distintas, em dias alternados, caso fosse necessário, para não prejudicar o estudante que realmente tivesse interesse. 
Id on Line Revista Multidisciplinar e de Psicologia

Id on Line Multidisciplinary and Psycology Journal

A verdade é que todos nós somos avaliados o tempo todo, em qualquer situação, seja em casa com a família, seja no trabalho ou no lazer. Com o professor não é diferente, ele é avaliado assim que entra pela primeira vez em sua sala de aula, seus alunos avaliam seu modo de vestir, de andar, de falar, de ensinar, embora não tenham a noção ou entendimento que estão avaliando, mas sabem dizer o que gostam e o que não gostam no novo professor.

É comum, principalmente em comunidades pequenas, professores investigarem com o professor do ano anterior como é a turma, o que já sabem, quais suas dificuldades e se tem muitos alunos "danados" ou indisciplinados. Essa postura investigativa parece ser positiva no ponto educacional, no entanto, o que vai sobressai na mente do profissional serão os nomes dos "ruins" da turma. Estes são os que mais precisam de cuidado, porém o cuidado dispensado à turma não será no sentido de aceitação, de zelo, de amor, mas de chegar "armado", cheio de preconceitos, desde o primeiro contato para mostrar quem manda, e a quem eles devem temer.

$\mathrm{O}$ ato de acolher o educando, não quer dizer que a situação cognitiva dele seja agradável, que o aprendizado esteja alto, mas que o professor aceitará tudo como realmente é, sem máscaras, e a partir da constatação da realidade se dispõe a fazer algo novo, que possa proporcionar esperança aquele que está pronto para desistir.

O educador Paulo Freire, (2002, p. 20) discorre muito bem sobre a necessidade do pensar certo: "Ensinar exige risco, aceitação do novo e rejeição a qualquer forma de discriminação", nesse sentido que o profissional que concluiu uma formação para o magistério estiver preso a pensamentos rígidos e tradicional da sua época de infância, será um completo desastre na sala de aula. Não adianta ir para escola disposto a punir alunos rotulados, tidos como o problema da sala, nesse caso, é preciso buscar ferramentas, dispositivos ou investimento pessoal para tocar esse ou esses alunos, de maneira que vejam na figura do professor um amigo, um refúgio, um companheiro que está do seu lado nos seus piores defeitos, não um carrasco ou ditador.

Quando o docente decide recusar um discente por motivos banais, mesmo que os motivos não sejam banais, seja por qualquer julgamento, as consequências são terríveis para este aluno, conforme nos diz Luckesi, (2000, p. 9) a seguir:

A recusa pode se manifestar de muitos modos, desde os mais explícitos até os mais sutis. A recusa explícita se dá quando deixamos claro que estamos recusando alguém. Porém, existem modos sutis de recusar, tal como no exemplo seguinte. Só para nós, 
em nosso interior, sem dizer nada para ninguém, julgamos que um aluno $\mathrm{X}$ 'é do tipo que dá trabalho e que não vai mudar'. Esse juízo, por mais silencioso que em nosso ser, está lá colocando esse educando de fora. E por mais que pareça que não, estará interferindo em nossa relação com ele. Ele sempre estará fora do nosso círculo de relações. Acolhê-lo significa estar aberto para recebê-lo como é. E só vendo a situação como é podemos compreendê-la para dialogicamente, ajuda-lo.

Mediante reflexão fica claro o poder que o docente exerce sobre o educado, este que é vítima da recusa interna do professor, de forma sútil e intencional, é sem sombra de dúvida o mais prejudicado, está correndo o grave risco de serem boicotadas suas chances de crescimento e desenvolvimento intelectual. É muito fácil para o docente pensar que é o dono da verdade, tem a caneta e o "poder" nas mãos, fazendo assim, como desejar com a avaliação do seu aluno trabalhoso, daquele que todos já te falaram mal, e que a sua fama não é muito agradável. Daí cabe-nos perguntarmos nesse momento: Que chances esse aluno terá nas mãos desse professor? Ele conseguirá sobressair dessa situação ou ficará a mercê da vontade do professor? Se ele não for aprovado, e isso se repetir durante anos, qual será o seu futuro na sociedade? O professor teve "culpas?".

Avaliar o aluno de forma responsável significa avaliar no processo, em diferentes situações, em momentos oportunos ao avaliado e não somente ao avaliador, nesse caso, o professor.

\section{Instrumentos Avaliativos}

Os instrumentos devem ser variados, diversos, flexíveis e acolhedores. Eles não devem limitar-se apenas a provas escritas, eles podem e devem variar. Além das costumeiras avaliações escritas, objetivas ou subjetivas, pode-se fazer exame oral, seminário, questionário, pesquisa, trabalho em dupla, trabalho em grupo, observação participativa, observação prática, enfim, existem diversas maneiras de avaliar. Infelizmente a prova escrita descritiva ou de assinalar ainda é a mais utilizada pelos professores.

Sabe-se que a avaliação escolar não age por si só, de forma aleatória, ela sempre estará pautada e fundamentada num conceito teórico, em princípios éticos, políticos e morais de ensino da instituição avaliadora, como afirma Caldeira (2000, p. 122): 


\begin{abstract}
A avaliação escolar é um meio e não um fim em si mesma, está delimitada por uma determinada teoria e por uma determinada prática pedagógica. Ela não ocorre num vazio conceitual, mas está dimensionada por um modelo teórico de sociedade, de homem, de educação e, consequentemente, de ensino e de aprendizagem, expresso na teoria e na prática pedagógica.
\end{abstract}

Muito bem lembrado, que a avaliação não é um fim em si mesma, mas um meio, meio este utilizado pelo professor para medir o grau de aprendizagem de seus alunos. Moretto (2005, p.96) afirma que: “Avaliação da aprendizagem é um momento privilegiado de estudos e não um acerto de contas".

Nesse mesmo sentido, sobre o ato de avaliar Perrenoud, (1998, p. 03) afirma o seguinte:

O sistema tradicional de avaliação participa de uma chantagem, de uma relação de força mais ou menos explícita, que coloca professores e alunos e, mais geralmente jovens e adultos, em campos opostos, impedindo sua cooperação.

As avaliações escritas podem ser objetivas ou subjetivas conforme foi dito anteriormente, mas na prática as duas são bem diferentes e podem surpreender o avaliador na sua correção. Por um lado às avaliações objetivas são diretas, como o nome já sugere, com linguagem clara e sem meios termos, o avaliado só pode acertar ou errar. Já as avaliações subjetivas são mais flexíveis, não que o aluno pode dar qualquer resposta às questões do exame, mas sim, pode expressar a resposta certa dentro do que realmente sabe, do que de fato aprendeu. Quanto às correções dessas avalições elas são mais trabalhosas, exige maior atenção do professor, leitura, análise e ponderação para "medir" ou atestar que seu aluno aprendeu ou não, atribuindo-lhe uma nota merecida.

Nas avaliações objetivas o esforço do professor para corrigi-las é menor, basta-lhe apenas seguir uma chave de correção para conferir as alternativas corretas. Nesse momento o docente não está pensando se o aluno aprendeu ou não, nem se ele quis dizer algo diferente do que está escrito, não tem como considerar meio ponto ou certo parcialmente, ele vai avaliar pelo que de fato foi assinalado. 
Id on Line Revista Multidisciplinar e de Psicologia

Id on Line Multidisciplinary and Psycology Journal

Segundo Hoffmann, (2003, p.46) contribuindo sobre o papel da avaliação escolar: “A medida, em educação deve resguardar o significado de um indicador de acertos e erros. Esse indicador passa adquirir sentido a partir da interpretação pelo professor do que ele verdadeiramente representa [...]" Assim sendo, fica claro que a avaliação nada mais é do que uma de muitas ferramentas pedagógicas, utilizada de maneira consciente, coerente e ética para aferir o estágio ou fase do conhecimento do estudante para daí progredir no ensino.

\section{Postura do Professor Mediante a Avaliação}

Sabe-se que alguns professores usam a avaliação como ferramenta de castigo, como vingança contra o aluno, especialmente aqueles mais trabalhosos, irrequietos e que adoram desafiá-lo, mas isso já foi dito anteriormente que não está certo.

O renomado escritor Hamilton Werneck, no seu livro "PROVA, PROVÃO, CAMISA DE FORÇA DA EDUCAÇÃO”, (1995) faz uma crítica aos sistemas de avaliação, e faz uma analogia entre o professor e alguns animais, os quais veremos a seguir:

\section{O Professor "macaco"}

Com propriedade Werneck, (1995, p.17) coloca esse tipo de professor como "professor-macaco", quando avalia seus alunos tem prazer em comentar as provas aplicadas, dando ênfase as questões erradas e ao mesmo tempo ridicularizando os alunos que erraram diante da turma. Esse professor acredita que assim e com muitas gargalhadas da turma possa melhorar sua relação, triste engano, pois alguns alunos ficarão profundamente humilhados, decepcionados consigo mesmo por ter sito tão ruim na prova. Já com o docente se não havia um bom relacionamento, agora é que não haverá mesmo, a postura infantilizada e erronia dele rompeu com qualquer chance.

O macaco animal é um animal interessante, gosta de brincar, de está no centro das atenções, em todos os palcos de zoológico sempre tem um bichinho tirando olhares da plateia. Para o animal esse comportamento é viável e legal, mas para um professor não pega bem, 
Id on Line Revista Multidisciplinar e de Psicologia

Id on Line Multidisciplinary and Psycology Journal

principalmente quando ele está rindo e fazendo ri de sua própria turma, fruto do seu trabalho, repito, fruto do seu trabalho. Então debochar de seus alunos é o mesmo que debochar de si mesmo, a sua turma é aquilo que você faz dela.

Sabe-se que nem tudo depende do professor, este não tem o poder de mudar todas as situações fracassadas, mas algo ele pode sim fazer por seus alunos. Muitos dos estudantes apegam-se, espelham-se no mestre para continuar estudando e sonhando com um futuro melhor. Por isso, depende muito do professor, se ele é dedicado ou relapso, animador ou desestimulador, inovador ou repetitivo, enfim, o professor tem de certa forma o "poder" em suas mãos. É claro que há situações que fogem do seu alcance, do seu controle, ficando ao encargo de entidades ou órgãos superiores.

\section{O Professor "João-de-Barro"}

O João-de-barro (Furnarius rufus), também conhecido como forneiro, é um pássaro pertencente à ordem dos Passariformes e à família Furnaridae (FIGUEIREDO, 1995, p.1). É conhecido por seu característico ninho de barro em forma de forno. Constrói sua casa amassando barro e moldando junto com sua parceira as paredes. Trata-se de uma ave habilidosa que constrói seu ninho, feito de barro e semelhante a um forno, no alto de postes, nos troncos de árvores e até mesmo nos paus dos currais.

É comum que as construções sejam em árvores, porém o João de Barro toma cuidado na escolha do local da porta de entrada por conta dos ventos, para que possam viver em harmonia com o meio ambiente, programando-se conforme a lei da natureza. Essa cautela nada mais é do que desejar o melhor para sua família, zelar pelos filhos, e conhecer muito bem os perigos naturais.

Ser professor João de Barro na visão do autor significa que ele como mestre construiu algo, deixou um legado na mente e no coração dos seus alunos. Assim, como a ave sente o vento, o docente sente os anseios, os medos e percebe as aptidões de sua clientela e procura reforçar os pontos positivos, valorizá-los e por em segurança, demonstrando que nele pode confiar. Nesse sentido, avaliação não será uma ameaça e sim uma etapa do processo. 
Id on Line Revista Multidisciplinar e de Psicologia

Id on Line Multidisciplinary and Psycology Journal

\section{O Professor "Serpente Venenosa"}

A palavra serpente é definida no dicionário Ferreira Júnior como "nome comum a ofídio, especialmente aos venenosos" (2011, p.807). Sabe-se que as serpentes são venenosas e não venenosas, embora para o leigo no assunto não saiba fazer a distinção, ocasionando medos e reações violentas no mesmo. Se não sabe qual serpente tem veneno e qual não tem, ninguém quer esperar para ser picado, embora o ataque só ocorra quando o animal se sente ameaçado. Mesmo assim, o homem irá ataca primeiro, matando imediatamente o animal, mesmo que este não seja uma ameaça revelada.

O processo de avaliação deste professor ou professora é claramente marcado por questões traiçoeiras, retiradas de rodapé de velhos livros, questões feitas para pegar no contrapé até os alunos mais espertos. A serpente é especialista em elaborar provasarapucas. Não são questões para verificar se o aluno aprendeu, mas para verificar se ele é capaz de escapar aos enganos escondidos em palavras de duplo sentido, coisas capciosas naquele estilo em que o elaborador da questão já tem certeza, a priori, de que será muito difícil acertar. (WERNECK, 1995, p.27)

Mediante reflexão acima, nos resta pedir desculpas as serpentes por tal comparação, pois a mesma só ataca quando se sente ameaçada e por instinto animal, já que é irracional. Mas o professor serpente é mais ofensivo que uma serpente real, pois ele está lidando com seres humanos, seus semelhantes e é formador educacional. Agindo de forma traiçoeira, com emboscada nas avaliações para derrubar o aluno é pura covardia, primeiro porque o aluno não é ameaça, segundo a avaliação vai retratar a realidade de seu trabalho, como mencionado anteriormente.

Para esse tipo de professor a palavra contextualização é uma palavra desconhecida do seu vocabulário, e pode até não ser, mas na hora de elaborar a avaliação escrita faz questão de armar situações enganosas, estilo bem distantes do que de fato ensinou. Reafirmamos sim, que as serpentes não merecem tal comparação, elas são melhores, são superiores. 
Id on Line Revista Multidisciplinar e de Psicologia

Id on Line Multidisciplinary and Psycology Journal

\section{O Professor "Castor"}

O castor é um animal acostumando com baixas temperaturas e que são conhecidos por sua habilidade natural para construir diques em rios ara morar. Para construir sua toca o castor utilizam troncos de árvores, que derrubam com seus poderosos dentes. Mesmo derrubando diversas árvores o castor não prejudica a natureza, o ecossistema não é afetado, e sim ajudado, pois seus diques podem gerar benefícios para o meio ambiente; entre outras coisas, estas barreiras propiciam a criação de lugares úmidos, ajudam a controlar inundações e eliminam contaminantes da corrente. "Apesar da grande quantidade de árvores que devastam, os castores não costumam prejudicar o ecossistema em que vivem" (XAVIER, 2010, p. 14).

O professor castor é semelhante a este animal, prepara seu dique para levar a enfrentar rigorosos invernos de aprendizado difíceis ou com baixas temperaturas, na prática, de baixas notas nas avaliações. Esse profissional segundo Werneck trabalha com a natureza a seu favor, mesmo que o inverno seja forte, ele não se entrega, não desanima e muito menos desanima a turma, seus alunos.

Ainda conforme o autor, ele ensina a persistir, a persistência leva o ser humano a não desanimar, mesmo que a turma seja considerada difícil, com alunos trabalhosos e com aprendizagem comprometida por inúmeros fatores. O professor castor confia no seu trabalho, quer o melhor para os seus alunos, aceita e reconhece a importância do trabalho coletivo, solicita apoio dos seus colegas quando precisa e se faz apoio dos seus colegas, quando necessário. Enfim, o castor "é excelente em auto - avaliação. Ele tem segurança do que fez e confia em sua obra, Ele sobreviverá". (WERNECK, 1995, p.31). O docente que assim age suportará as baixas temperaturas, os infortúnios da profissão e fará o que tiver ao seu alcance, pensando sempre no melhor do grupo, e para aprendizagem dos seus alunos.

\section{Avaliação Flexível frente à ameaça da marginalização social}

Cada ser humano é único, cheio de conhecimentos, particularidades e de capacidades diferenciadas, com isso nos resta esperar que as escolas estejam abertas ao novo, as mudanças 
de paradigmas, sair da rotina e atentar para um olhar flexível em suas práticas avaliativas. Sobre as diferenças individuais Saviani (1999, p.20) diz:

Eis a "grande descoberta": os homens são essencialmente diferentes; não se repetem; cada indivíduo é único. Portanto, a marginalidade não pode ser explicada pelas diferenças entre os homens, quaisquer que elas sejam: não apenas diferenças de cor, de raça, de credo ou de classe, o que já era defendido pela pedagogia tradicional; mas também diferenças no domínio do conhecimento, na participação do saber, no desempenho cognitivo.

Infelizmente vivemos numa sociedade marginalizada, onde grande parte da sociedade não tem acesso a direitos básicos, como moradia, alimentação, saúde e segurança, mas isso não significa dizer que o mundo está dividido entre ricos e pobres, brancos e negros, mas sim, entre aqueles que tiveram acesso a uma educação de qualidade, com sistema avaliativo flexível e aqueles que não tiveram acesso e oportunidade a mesma educação. Esse segundo grupo foi excluído logo nas primeiras avaliações tradicionais da escola, do professor sabe tudo. Sem contar que a sua origem pobre, lhe deu todos os requisitos para ser "tachado" como inferior, incapaz e dessa forma a escola não fez questão por sua vida, seus interesses, anseios e medos, expulsando-lhe ou atrasando facilmente no seu sistema avaliativo excludente e seletivo.

A pedagogia tradicional deixou o seu legado, isso não se pode negar, mas que massacrou e marginalizou muitos alunos carentes ou negros também não para esconder, nem se orgulhar dessa postura.

Hoje em dia as diferenças vistas nos homens não são mais a cor de pele, de crenças religiosas ou classe social, mas sobretudo de saberes, de desempenho cognitivo, de capacidade intelectual desenvolvida por aqueles que driblam os sistemas avaliativos falíveis da educação.

Avaliação da aprendizagem não pode continuar sendo uma vilã e sim uma aliada na educação. Nesse sentido, Luckesi (2000, p.1) assim comenta:

Chega de confundir avaliação da aprendizagem com exames. A avaliação da aprendizagem, por ser avaliação, é amorosa, inclusiva, dinâmica e construtiva, diversa dos exames, que não são amorosos, são excludentes, não são construtivos, mas classificatório. A avaliação inclui, traz para dentro; os exames selecionam, excluem, marginalizam. 
Id on Line Revista Multidisciplinar e de Psicoloqia

Id on Line Multidisciplinary and Psycology Journal

Ficou clara a diferença entre avaliação e exame. Para o autor acima, a avaliação deve ser amorosa, incluir, trazer para sim, mostrar que está do lado do aluno, enquanto os exames não incluir, mas exclui e marginalizam, colocando o avaliado sob forte pressão, e o professor como o senhor da verdade, detentor de todo saber, porém, um ditador que não aceita ser questionado ou contrariado, sob pena de castigo na hora da correção do exame.

\section{Considerações Finais}

Para que os processos avaliativos executados em sala de aula venham de fato contribuir para a aprendizagem é necessário que haja uma dialogo entre professor e aluno, visando discutir harmoniosamente o que pode ou não contribuir para melhorar o processo de ensino aprendizagem.

A avaliação é tarefa do professor, o qual está inserido num sistema de regras e ideologias, que por sua vez avaliar bem ou avaliar mal está fundamentado no que a instituição acredita e defende como missão.

A relação professor aluno é algo muito sério e que deve ser observada com apreço. Se essa relação for afetada por práticas distantes da realidade esperada, trará o surgimento de um processo prejudicial na vida do aluno. Primeiro este não renderá na escola, não aprende o que o professor pensa ensinar, fracassado nas avaliações escolares corre o risco de ser reprovado e até marginalizado por sua condição negativa perante as expectativas de uma sociedade capitalista e competitiva.

Entretanto, cabe ressaltar que não adianta procurar culpados pelo fracasso escola, não há um só culpado. Cabe-nos correr atrás de soluções possíveis, alternativas de avaliações diferenciadas e coerentes com a prática em sala de aula a fim de atrair a atenção do estudante no momento do ensino, para que este não se perca na avaliação.

Dentre os animais comparados com o professor, ficou evidente que professor macaco, João de barro e a serpente venenosa não são os melhores exemplos a serem seguidos, embora com suas qualidades particulares. A melhor opção, ou seja, uma das comparações mais viáveis se dar com o castor, professor experiente que conhece bem o seu ambiente e sua clientela, sabe exatamente onde está atuando. Independente dos problemas enfrentados com a turma, ele 
sempre está disposto a buscar o melhor para os seus alunos, pelo seu trabalho. Além de tudo isso, antes de qualquer julgamento avaliativo, demonstra segurança e estimula confiança na hora da avaliação para que o avaliado sinta-se bem, livre para buscar soluções no seu entendimento, dentro de sua capacidade, e sem medo de errar, já que o momento da avaliação condiz com outras atividades do dia a dia em sala de aula.

\section{Referências}

CALDEIRA, Anna M. Ressignificação a avaliação escolar. In. Comissão Permamente de Avaliação Institucional: UFMG-PAIUB. Belo Horizante: PROGRAD/UFMG, 2000.p.122-129 (Caderno de Avaliação, 3)

COSTA, Jamili Souza. A avaliação da Aprendizagem Escolar. Saberes e Práticas Docentes. Ilhéus12-a14 de agosto de 2013. I JORNAPED.

DIAS, E.G.; OLIVEIRA,G.F. Avaliação Institucional e da Aprendizagem na Escola de Ensino Infantil e Fundamental Joaquim Caboclo. Id on Line Revista de Psicologia, Janeiro de2017, vol.10, n.33,p. 337-346. ISSN: 1981-1179.

FERREIRA JÚNIOR, Aurério Buarque de Holanda. Dicionário escolar de língua portuguesa/ Coordenação de Marna Baird Ferreira e Margarida dos Anjos; ilustração Axel Sande - 2. ed. Curitiba: Positivo, 2011.

FREIRE, Paulo. Pedagogia da Autonomia. Saberes Necessários à Prática Educativa. São Paulo:EGA. 2002.

LUCKESI, Cripriano Carlos. O que é mesmo o ato de avaliar a aprendizagem? Disponível em Pátio On-line. Pátio. Porto Alegre: ARTMED. Ano 3, n. 12 fev./abri.2000.

2008.

Avaliação da Aprendizagem escolar: estudos e proposições. 19. Ed. São Paulo: Cortez,

MORETTO, Vasco P. Prova- um momento privilegiado de estudo - não um acerto de contas. 3 ed. Rio de Janeiro: DP\&A, 2005.

PERRENOUD, P. Avaliação: da excelência à regularização das aprendizagens: entre duas lógicas. Posto Alegre. Artmed, 1998.

HOFFMANN, Jussara. Avaliação: mito e desafio: uma perspectiva construtivista. 32.ed. Porto Alegre, RS: Medação, 2003. 
SAVIANI, Derrneval. Escola e democracia: teorias da educação, curvatura da vara, onze teses sobre educação e política! Dermeval Saviani.- 32. ed.- Campinas, SP: AutoresAssociados, 1999. (Coleção polêmicas do nosso tempo; v.S)

WERNECK, Hamilton. Prova, povão, camisa de força da educação: uma crítica aos sistemas de avaliação crivada de humor e propostas. Petrópolis:VOZES, 1995.

SAKAMOTO, Bernardo Alfredo Mayta; Verástegui, Rosa de Lourdes Aguilar. Avaliação como ato de amor e não de exclusão. XXI Semana de Pedagogia: Infância, Sociedade e Educação, 13-15 de outubro de 2010.

XAVIER, Carlos. Desponível em: http://pequenozoologo.blogspot.com.br/

\section{Como citar este artigo (Formato ABNT):}

LOPES, E.S.; CARVALHO, A.C.F. Avaliação da aprendizagem: Um desafio para o docente. Id on Line Revista Multidisciplinar e de Psicologia, Janeiro de 2017, vol.10, n.33, Supl 2. p. 304-319. ISSN: 1981-1179.

Recebido: $22 / 12 / 2016$

Aceito: $19 / 01 / 2017$ 